mr Tatjana Adlešič, general manager, Špica d.o.o. Metlika

mr Ervin Kazić, hotel manager, M Hotel, Ljubljana

Jani Toroš, PhD, assistent profesor, IMI - Innovative management institute, Ljubljana

UDC 338.488.2:640.412

338.487:339.162.4]:004.738.5

\title{
SHAPING THE OFFER OF HOTEL SERVICES FOR INTERNET SALES
}

\begin{abstract}
This paper deals with the consumer's preferences in booking hotel services over the internet. A conjoint analysis was used in establishing whether the price is the most important factor in deciding on a hotel service and which elements of the service can be used as a competitive advantage. Although the price does play a pivotal role in the consumer's decision, within an acceptable price range he will take into account the bonuses offered by the hotel. Among the bonuses, free
\end{abstract}

\section{Introduction}

Tourism is one of the most important industries and one of the pillars of globalization. And within this sector, it is the hotel industry that is one of the mainstays of tourism. The sales of hotel services and the buying habits of consumers in the last twenty years have changed completely. With the development of communication technology and new information technologies, direct marketing is becoming increasingly developed, especially e-commerce (online shopping) for products and services (Belanger, Hiller and Smith 2002). With the aid of online reservation systems, the Internet, being one of the main distribution channels, supplies information about virtually all providers of hotel services for any given destination in one spot. All hotel service providers have the same sales starting point. The purchases made by consumers have to do parking and free internet access play an important role, while free access to pornographic films and free wine with dinner are not an important factor. Room colour does not play a role in the consumer's decision making process regarding hotel services.

Key words: hotel service, conjoint analysis, decision-making, consumer bonuses, the Internet.

with decision-making. Neil Salerno (2008), a hotel management expert, says that at least $70 \%$ of travellers make their hotel reservations online. A typical consumer makes his choice based on the information he finds on the Internet. He normally makes decisions individually and intuitively.

\section{Definition of the research - subject matter}

Hotel management is facing modern marketing approaches. Internet tools, such as Google AdWords, offer hotels a chance to get a higher ranking in a search engine's result page. However, it is still a long way from this to the moment when a consumer decides to make a purchase. In less developed environments, competition mainly takes place at the level of the expected product. According to Toroš $(2009,17)$, competition in the area 
of services in Slovenia also takes place at the level of the expected product. The hoteliers have to design an enriched or extended product. It is, however, worth mentioning that there is some discrepancy among authors regarding which elements should be considered the integral part of the expected product and which ones are to be the integral part of the extended product.Hotels can be divided into many different categories (segments). The essential elements for city hotel services are not necessarily important for a hotel located somewhere high in the mountains.

In theory, there are various different types of price formation in the hotel industry. The Slovenian professional literature offers very few solutions regarding the hotel industry. The authors who get quoted most say that the selling price (Melavc 2003, 39) is set in one of two ways. The first one is based on the laws of supply and demand. The second one is based on a cost-related starting point whereby the selling price is set by adding a suitable markup to the cost price. According to Mihalič (1999b, 76-77), three approaches are used for price formation: price formation based on demand, price formation based on costs and price formation based on competition. The two authors of a textbook intended for future tourism workers (Prodnik in David 2009) define the selling price of an overnight stay in two ways: based ,either on total or variable costs per unit”. The authors put forth two methods: the "dividing method" and the "method of equivalent numbers". Both are intended for calculating costs after a service has already been completed. Foreign literature (Kasavana and Brooks 2005, 419-509) offers more useful methods for fixing prices since the authors, as opposed to the majority of Slovene authors, also write about planning models and the connected pricing. Pricing is a complex issue that requires plenty of factors to be taken into account. This issue is covered by Toroš (2010) who analysed pricing from different perspectives in his publication. The price of a pro- duct is not merely connected to determining its costs and adding a markup. Especially in the hotel industry as this is an activity with high fixed costs per product unit. It requires considerable investments into tangible fixed assets and has low capacity utilization due to demand variability. The invested capital is therefore poorly utilized and the high fixed costs get distributed between a small quantity of products (Planina 1997, 184). Another typical feature of a hotel product are fluctuations in the occupancy rate. The only profit comes from selling a room/overnight accommodation. It is therefore extremely important to plan the hotel occupancy and the pricing which is connected to it. A hotel can have different prices for its guests within the same term. Below we also specify the diversity of prices with regard to the segments of hotel service users. Occupancy is very important for determining the price. Finally, it is important to add that when authors discuss the cost-related aspects of pricing, they tend to forget one of the crucial elements of overnight accommodation and the related costs, namely the period of staying in a hotel. In compliance with the Rules on Criteria and Method for the Categorization of Accommodation Facilities and Marines (The official Gazette of the Republic of Slovenia, no. 62/2008), a hotel has to provide certain services such as turndown services, changing the hotel linens and towels. These are some of the factors that influence the variable costs. There is a substantial difference in having a guest staying for one or two nights, which is the average accommodation period in Ljubljana hotels, or having a guest staying for more than three nights, which is typically the case in resort hotels. Below, we provide some possible solutions regarding the fixing of prices with the emphasis on the abovementioned points. The hotel industry is facing what could be termed "new economics". There has been a significant increase in purchasing overnight accommodation through online reservation systems. In the case of 
the service industry where a product is used outside the place of residence, what becomes important is the information based on which a consumer decides whether or not to make a purchase or to compare alternatives for the potential purchase.

Decision-making can be regarded as an outcome of mental (cognitive) processes, leading to the selection of a course of action among several alternatives. Every decisionmaking process produces a final choice. The output can be an action or an opinion of choice (Reason 1990).

The objective of this paper is to determine which elements and to what extent enriched or extended hotel services influence the decision-making process of a consumer who is making a purchase through an online reservation system or is using the Internet to look up information for a later purchase. What role is played by hotel bonuses in relation to the price? Most of all, we are interested in finding out which of the offered bonuses the consumer is going to prefer. Another aspect to take into consideration is the colour of the wall in a hotel room. We are interested in finding out which of the offered colours the consumer is going to pick. We wish to find out how much attention a consumer pays to individual elements of the offered hotel service when deciding whether or not to make the purchase. The service will consist of room colour, bonus and price.

This text deals with a hotel service as equivalent to a product. According to $\mathrm{Du}$ brovski (2006, 243), when we talk about a product we are also referring to services, capital, technology and know-how.

\section{Purpose, objectives and hypotheses}

The purpose of this paper is to use a theoretical basis defining purchase-related decision-making and the elements of the marketing mix in order to examine the level of influence that the offered elements of hotel services have on the decision whether or not to make a purchase online. Different combinations of facets consisting of different elements will be offered for choice. The facets consist of three elements: colour of the room, bonus and price.

The available room colours are: green, blue, violet and brown.

The available bonuses are: complimentary house wine at dinner, free $\mathrm{Wi}$-Fi service, free viewing of pornographic channels and free parking.

The offered prices are set at six-euro intervals: 64 EUR, 70 EUR, 76 EUR and 82 EUR.

The objectives of this paper are:

- analyzing the professional literature (in the theoretical part of the paper) in the fields of decision-making, hotel industry and hotel service marketing;

- analyzing the influence of individual elements of the offered hotel service on the consumer's purchase decision (in the empirical part of the paper);

- suggesting guidelines and recommendations to the hotel management for setting up an extended hotel service based on the findings;

- based on the findings, suggesting guidelines and recommendations to the owners of the hotel and the hotel management regarding the use of a specific room colour when renovating the hotel, use of bonuses when selling hotel services and price formation in connection with the other two elements of the hotel service offer.

The following three hypotheses will be presented in the paper:

$\mathrm{H} 1$ : Price is the most important factor in deciding whether or not to purchase a hotel service.

$\mathrm{H} 2$ : The room colour is the least important factor in deciding whether or not to purchase a hotel service.

H3: Of the four bonuses on offer, the free $\mathrm{Wi}-\mathrm{Fi}$ Internet access is the most important factor in deciding whether or not to purchase a hotel service. 


\section{Methods of research}

In the paper, we will focus on the quantitative research by using a conjoint analysis. The request for filling out our questionnaire will be sent to 400 email addresses. According to Orme (1998), 30 to 60 answers supplied with the help of conjoint analysis are sufficient for proving hypotheses and conducting research. The conjoint analysis reduces the problem of consumers saying one thing while doing and choosing something else. The results obtained with this technique are more reliable and more valid (Walley, Parsons and Bland 1999). By implementing the conjoint analysis, it is possible to avoid insincere answers to the survey questions, whereas in a standard survey, the respondents often give the kind of reply that the questioner would like to hear (Rapalle 2006, 14). Choosing colours and bonuses are typical individual decisions; they depend on each individual's taste. If we asked the respondents about choosing a hotel room colour, the simplest and most obvious choice would probably be white. It would be much more difficult to get useful answers when asking the guests about bonuses. The decision would most likely be influenced by rationally considering what the appropriate answer might be. Due to traditionally unfavourable public opinion towards pornography, a free-of-charge access to pornographic channels as a bonus would most likely have a negative effect on the decision whether or not to purchase the hotel services.

\section{Suppositions and limitations}

The limitations are primarily connected to the lack of literature on models of purchase-related decision-making related to online shopping for hotel services. Shopping online and the related purchasing habits are rapidly changing. An additional problem is that online shopping is growing at incred- ible speed, as it is connected to the quickly developing technology. Surveys are difficult to compare because a few years between surveys lead to a totally different environment and offer new findings. Our research is based on the assumption that a consumer's decision to purchase a hotel service in a city hotel is made individually, quickly and intuitively, since the purchase cost is not very high as is the case with hotel services in holiday resorts. Research is intended for a city hotel where the average annual period of accommodation is 1.7 nights. We have drawn on the practical experience gained in the Ljubljana M Hotel, which has been one of the top hotels in Ljubljana in terms of its occupancy rate in the last 10 years.

\section{Decision-making factors}

In the traditional sales methods, the customer now plays an increasingly important and active role while the salesperson is becoming increasingly passive. The role of the salesperson has shrunk down to a "supplier" of information, rather than someone who requires persuasive skills. The customer is "convinced" when he assures himself that the time is right to make a purchase.

Many authors stress the importance of experiencing a product as a benchmark for purchasing that product, whether it is tangible or intangible. They emphasise the fact that purchasing a product solely for its practical use is not enough. The purchasing experience has to comprise of two elements, which affect the final decision.

Carbone and Haeckel $(1994,8)$ discuss the functionality of a product which covers its usefulness and price. The authors also talk about contextualizing the product (context clues). These clues stimulate the consumer's senses through smell, shape, colour etc.

According to Addis and Holbrook (2001, 57) experiences are formed by combining the objective characteristics of a product 
or service and the subjective reaction of a consumer. They state that each product has utilitarian properties, such as colour, price, shape, size and hedonistic properties that affect the consumer's thoughts and perception. And consequently his decision-making.

Based on what has been mentioned above, this paper highlights the use of colour as one of the important elements in purchasing hotel services.

\section{The decision-making process}

The decision-making process is one of the crucial factors of consumer behaviour (Peter and Olson 2002, 14). There has been a major shift in the area of consumer behaviour and decision-making in the last few decades, from understanding behaviour from the rational point of view to emphasising the importance of psychological and other decision-making factors (Bargh 2002, 280). The shift took place in the mentality of manufacturers and service providers; they have largely refocused their attention from the product to the customer (Wikström $1996,6)$. This was brought about by growing competition between companies, better quality data acquired through market research and the development of the Internet (Peter in Olson 2002, 5).

Consumers' decision-making is a cognitive process whereby the consumers interpret product information and integrate this knowledge in order to choose between available options (Peter and Olson 2002, 549).

The traditional approach regarding the knowledge of consumer's habits was based on the supposition that a customer makes rational decisions and has predetermined and clearly defined preferences (Niva in Timonen 2001, 332). Three models regarding consumer behaviour emerged in the 1960s and 1970s (Erasmus, Boshoff in Rousseau 2001, 83). The Nicosia Model that was proposed by Francesco Nicosia in 1966 deals with the process of choosing a product or brand. The model specifies four fields of operation: formulation of the consumer's views, searching for information and evaluation, the act of purchase and the post-purchase feedback process.

The second model dealing with choosing brands is called the model of consumer motivation and behaviour proposed in 1968 by Engel, Blackwell and Kollat.

These authors also viewed consumer behaviour as a process in which several initial factors influence the consumer's behaviour.

The third model was developed in 1968 by Howard and Steth and was for a long time considered the best consumer decisionmaking model.

All three models are based on the premise that all the necessary information about the product and the effects of its use are available to the customer. Having weighed all the options, the customer then decides for the one that is most beneficial to him. The three models are collectively known as the rational choice theory.

The second approach developed from the idea that consumers use simplified decision-making methods when taking decisions. They reduce the complexity of a given problem and simplify the choosing process. Consumers want to make good decisions and simultaneously reduce the cognitive effort in reaching these decisions (Niva in Timonen 2001, 332).

One of the most important approaches is the cognitive processing model by Peter and Olson $(2002,50)$ that treats consumer decision-making as a way of solving problems by focusing on objectives. There has been a noticeable shift in the development of decisionmaking and consumer behaviour theories from rationality to psychological and social factors of decision-making. Complicated behavioural and decision-making models attempt to encompass as wide a spectrum of products as possible; however, the complexities of the environment, sales conditions and 
specificities of products makes it impossible to apply these models to different situations. Each situation requires a new model precisely because of its specificity and the peculiarities of each individual product (Erasmus, Boshoff and Rousseau 2001, 87).

Developing a suitable consumer decision-making model in a given situation is of great importance for a company, since this is the right method for understanding consumers and the path to a successful marketing strategy.

From the consumers' perspective, the marketing strategy of a company is a collection of stimuli in the environment surrounding them and influencing the consumers' emotions, intellect and behaviour.

From the company's perspective, a marketing strategy is connected to target groups with which the company wants to establish the kind of exchange that will satisfy the expectations of the consumer and the company (Kotler 1996, 13).

Most of the decisions we make are unconscious. Nightingale (2008) suggests that we decide without being aware of how the decision-making processes function. Exploring all the available alternatives in our daily lives would take up too much of our time.

Pagon $(2011,1)$ states that decisionmaking is a selection process between two or more alternatives. He puts forth two types of decisions:

- programmed (repetitive, routine, made on the basis of well-known principles or rules);

- unprogrammed (new, original decisions that are not based on any established instructions, principles or rules; they require creativity).

Decision-making is always a response to a specific problem and taking a decision is part of the problem solving process. The problem solving process has six steps or stages.
1. Identifying and defining the problem: this step is also often referred to as diagnosing the problem and it deals with comparing the current situation with a certain standard or the desired situation as well as explaining the reasons for the established discrepancies.

2. Seeking and developing alternative solutions: at this stage, we attempt to find as many different ways of solving a given problem as possible through creativity and imagination.

3. Assessment and comparison of alternatives: trying to determine all the benefits and shortcomings for each of the specified alternatives.

4. Selecting one of the solutions: out of all the alternatives, we choose the one that seems best and most suitable with regard to the current situation.

5. Implementing the solution: putting a solution into action in order to solve a problem; we do everything that is necessary for the full implementation of the solution.

6. Observing, monitoring and evaluating the effects of the implemented solution: by objectively monitoring the situation and changes, we try to assess whether the problem has been successfully solved by implementing the selected solution. In case of derogations, corrective measures should be undertaken.

\section{Selecting analytical tools}

The empirical part of the paper focuses on research that uses a method to measure the influence of an individual service characteristic on the service preference level - conjoint analysis. It is difficult to get truthful answers in surveys because the respondents do not typically reply in a sincere manner when answering questionnaires, but instead give the kind of reply they expect the questioner wants to hear (Rapalle 2006, 14). 
The conjoint analysis reduces the problem of consumers saying one thing while doing and choosing something else. The results obtained with this technique are more reliable and more valid (Walley, Parsons and Bland 1999).

\section{Conjoint analysis}

The conjoint analysis enables the provider of a product or service to establish which characteristics it should focus on when developing a new product or service. This analysis reduces the loss of time it would otherwise be required to develop the features of a product that are unimportant for the customer (Gustafsson, Herrmann and Huber 2003, 163). In the hotel trade, the sold product is exclusively linked to the date of overnight accommodation. The choice of hotel is very often connected to the information found on the Internet by a consumer. Assuming that a consumer quickly and intuitively decides to stay in a city hotel where the period of accommodation is very brief, we decided to perform the conjoint analysis.

This paper focuses on the question of to what extent individual elements of a particular product influence the decision whether or not to buy that product. The offer of additional services can be found in any hotel: free transfer service to the city centre, choice of pillows, free Pay TV, free sauna access, various shopping and swimming pool discounts.

We wish to determine how much the decision to buy a hotel service is influenced by bonuses which are part of promotional activities and present an expense for the hotel, but are considered an added value from the marketing perspective. We wish to determine whether physical aspects of the hotel service such as the colour of the room, choice of pillows, anti-stress beds and similar marketing tools, which in theory present an added value, actually affect the decision whether or not to make a purchase and how important they are for a consumer when deciding on the purchase.

When it comes to the conjoint analysis, a consumer is not concerned with making a purchase, but in fact chooses between combinations of hotel services comprising of different elements. Therefore, the implementation of this analysis also has to do with a potential purchase. The results of the analysis allow us to make a suggestion for a hotel product/service contributing to the purchase-related decision.

\section{Presentation of the conjoint analysis}

The conjoint analysis is used to measure and determine what the consumer favours when choosing a product or service. Each product consists of certain characteristics such as, for example, car speed, size of the boot, fuel consumption, etc. A hotel service can be broken down into location, room colour, wine offer, Internet access, etc. A consumer associates all these characteristics with the price. A consumer's interest is expressed in terms of wanting the highest level of a product's given feature for the lowest price possible. On the contrary, it is in the interest of the provider to set the highest possible price with minimum costs (Toroš 2009, 71).

Conjoint analysis is based on the premise of taking into account the desired characteristics and leading us to a product or service comprising of the lowest level of individual features that a customer is still willing to accept and minimum costs for the provider which are in turn expressed in the lowest level of individual characteristics of a product or service. This method allows us to establish what product composition (combination) is optimum for the achieved price. 


\section{The conjoint analysis applied to the hotel industry}

When Marriott considered starting a new brand/chain of hotels for business travellers, which later became known as Courtyard by Marriott, they hired marketing experts to help them come up with a new hotel concept. There are boundaries to what services and facilities can be offered by the hotel and at what price. Marriot wanted to find out which services and facilities in the hotel the consumers are willing to accept and which ones to relinquish in order to achieve value for money (Rodman 2011).

Marriott wished to find a market niche between full-service hotels and budget hotels, especially in locations where there was not much demand for highly categorized hotels. If such demand existed, then Marriott would fill that niche with a new offer. The conjoint analysis was used and 601 consumers from 4 large cities participated in the consumer study. The intention of the questioner was to determine what mix of attributes at a given price would achieve the highest level of satisfaction so 50 attributes were divided into 7 facets. The intention of the questioners was not only finding out which combination of attributes at a given price a consumer would accept, but also which attributes the consumer prefers, but would not be willing to pay for them (Wind et al. 1989, 25-47).

\section{Study}

We prepared an online survey, which was intended for foreigners and written in English. We used the existing list of contact information to select a random sample and send a request (invitation) by email asking the recipients to reply to the questions in the online survey. The mail also contained a link to the website with the online survey. The Sawtooth Software tool CBC (Choice-Based Conjoint) was used in the implementation of the online survey.

\section{Online questionnaire}

The questionnaire was divided into the introduction and three sets of questions.

The survey introduction is as follows: You are deciding on making a reservation for a hotel room in Ljubljana. You intend to spend no more than two nights at a hotel. We would like to know which combination of the offered hotel service you prefer. After each selection the combinations will be altered. Each combination consists of:

- room colour: blue, dark grey, green, violet or beige;

- bonus: complimentary house wine at dinner, free Wi-Fi service, free viewing of pornographic channels or free parking.

- price: 64 EUR, 70 EUR, 76 EUR and 82 EUR.

We also added a chance to reply: None of the above. 
Figure 1. An example of a questionnaire

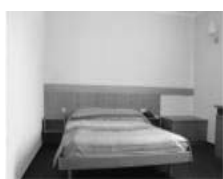

$\frac{\text { Bonus: }}{\text { free house wine at dinner }}$

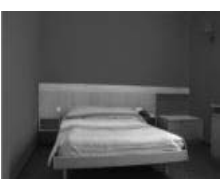

Bonus:

free viewing of pornographic channels

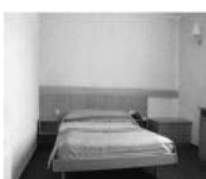

Bonus: free parking
(None: I wouldn't choose any of these)

$$
\frac{\text { Price: }}{76 €} \quad \frac{\text { Price: }}{82 €} \quad \frac{\text { Price: }}{70 €}
$$

After the conjoint questionnaire was completed we asked the respondents which of the listed colours they would choose because we wanted to know whether their selection of colours would match the colour preference results of the conjoint analysis. The listed colours were the same as the colours in the conjoint analysis: blue, dark grey, green, violet and beige.

The respondents had to reply which bonus they would choose at the hotel reception desk upon their arrival. The bonuses matched the ones in the conjoint analysis, namely: complimentary house wine at dinner, free Wi-Fi service, free viewing of pornographic channels and free parking.

Again we wanted to find out whether the selection of bonuses would match the results of the preferred bonuses in the conjoint analysis.

In the third set of questions, we asked the respondents about their gender and age. We divided the age into three groups.

We ended the survey by thanking them for their cooperation.

\section{The data collection method}

The survey invitation was sent to 400 email addresses from 7 email addresses. While 378 emails reached the addressees, 22 were returned undelivered or with the message that the recipient was unavailable. The addresses of recipients were chosen selectively.

The survey invitation was sent from the email address of the M Hotel to 114 addresses. We only included addressees whose name or name and surname were used in the email address. The request was not sent to addressees with the domain name of publicly available email service providers such as Gmail, Yahoo, Hotmail, etc. The addressees were chosen by selecting an average of five addressees for every letter of the alphabet. Seven email addresses returned the message that the emails were undelivered and one of the recipients was unavailable. We sent 71 survey questionnaires to students doing their degree at the Faculty of Management, the 2009/2010 generation. There were no rejections. Another survey invitation was sent to 50 addresses from one of the Slovenian banks through their head of marketing. Four requests returned undelivered. The survey invitation was also sent from one of Ljubljana's marketing agencies to 95 addresses. The same as with the M Hotel, all the recipient's email addresses contained their names and surnames. One of the emails was not delivered and two came back with the message that the recipient was unavailable. The survey invitation was sent from the email address of the author of this paper to 40 addresses. Seven returned undelivered. 
Questionnaires were also sent from two additional email addresses to 30 recipients and they were all delivered.

\section{Sample description}

The normal sample size of the conjoint analysis is between 150 and 1,200 respond- ents. Therefore 300 responses should be sufficient for a solid quantitative research (Orme, 1998). However, the author goes on to add that for the purposes of proving hypotheses and conducting research, 30 to 60 responses are sufficient, as was already mentioned in the introduction. We received 151 responses.

Figure 2. Classification according to gender

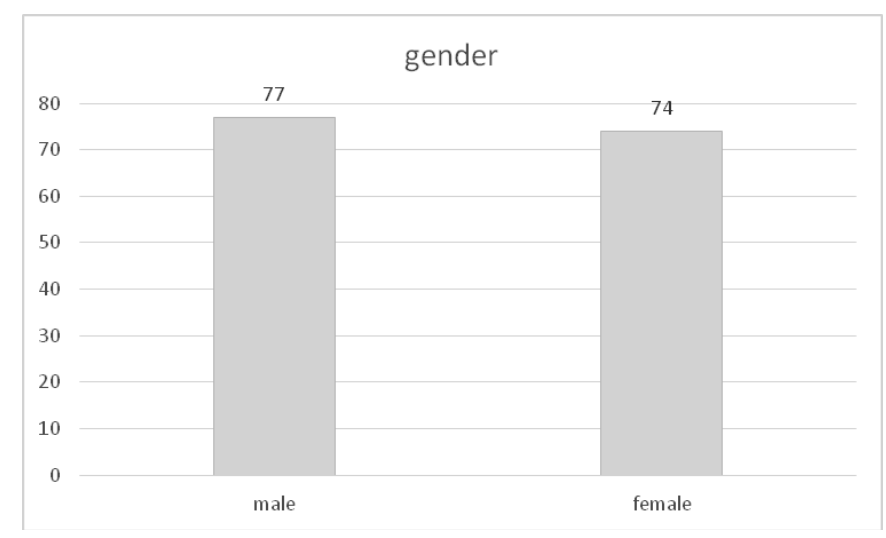

As shown in figure 2, there were 74 We wanted to receive at least $50 \%$ responses women and 77 men who respondents, which from men, as they are more frequent visitors meets the criteria we had set for this survey. to the M Hotel than women.

Figure 3. Classification according to age

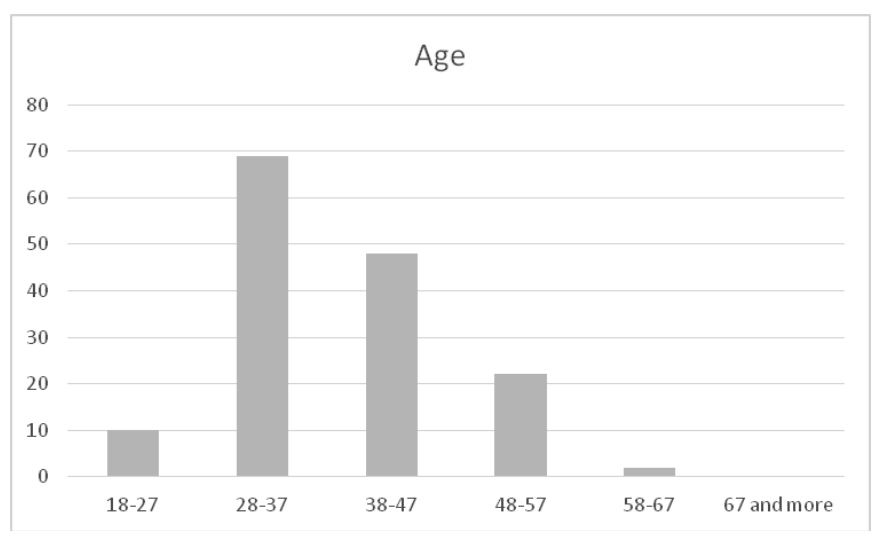


Figure 3 shows the classification according to age classes. They are distributed between all age classes except for people aged 68 or more, since surveys were only sent out to people considered to be economically active.

\section{Findings and interpretation of results}

The analysis was conducted based upon realistic assumptions.

The selling prices of rooms in the M Hotel that are listed in the analysis are realistic and are typically found within the given range. All the listed bonuses are an actual part of M Hotel's offer. The walls in hotel rooms are painted in combinations of two colours.

\section{The proportion of hotel service attributes}

The results acquired with the conjoint analysis show that the hotel service characteristics comprising of colour, bonus and price are proportioned as follows (expressed to the first decimal).

Figure 4. The proportion of hotel service characteristics

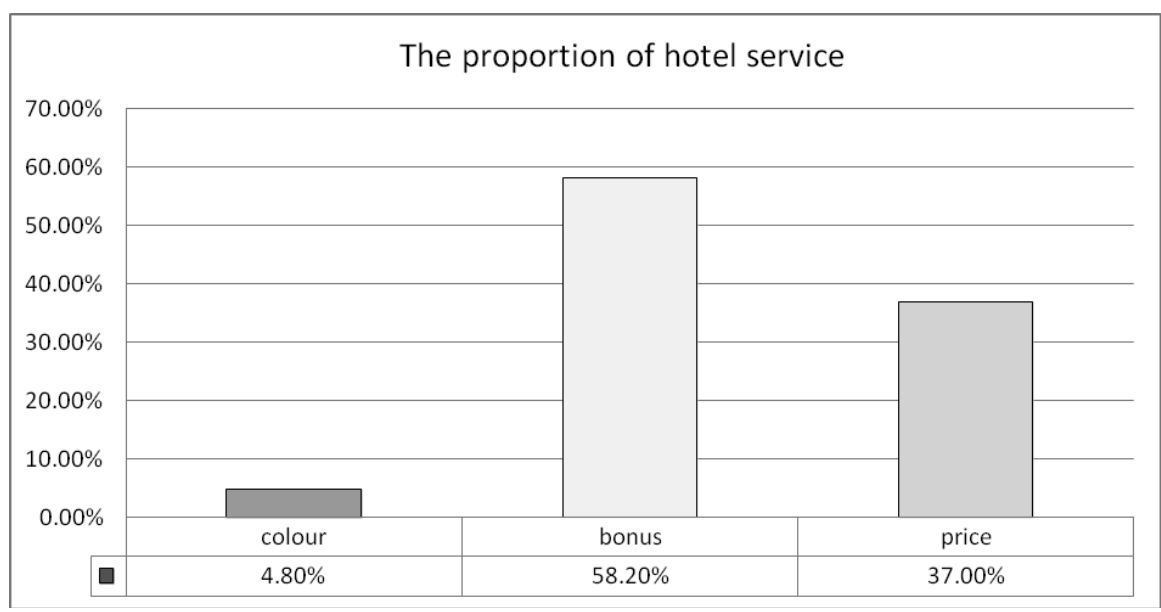

The largest proportion of hotel service characteristics is reached by the bonus with $58.2 \%$. The price reaches $37 \%$.

Hypothesis 1: Price is the most important factor in deciding whether or not to purchase a hotel service.

Figure 4 clearly shows that the bonus is more important than the price. The statement that the price is the most important factor in deciding whether or not to purchase a hotel service has been rejected.

Hypothesis 2: The room colour is the least important factor in deciding whether or not to purchase a hotel service.
The colour has the lowest proportion of all three hotel service characteristics with merely $4.8 \%$. This confirms our second hypothesis.

\section{Zero axis}

Individual characteristics of the hotel service will be shown on a zero axis, where zero means a neutral value and the other measured values are distributed into a negative and positive field. A high negative value of an individual attribute level reflects a minor importance while a high positive value reflects a major importance. The sum of all values is zero. 


\section{Colours}

We used the following colours in the conjoint analysis study: blue, dark grey, green, violet and beige.

Figure 5. Level of benefit: colours

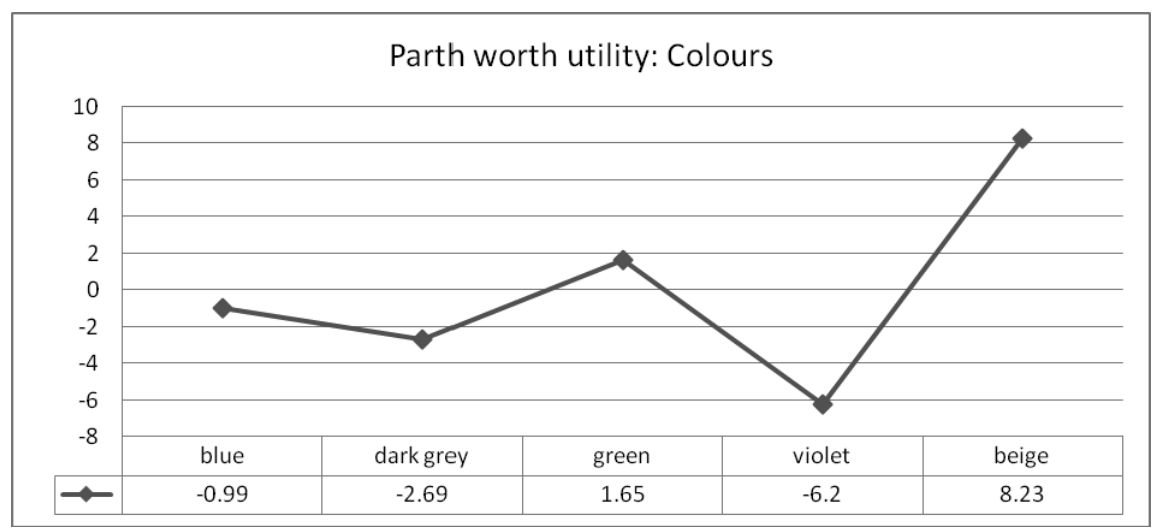

As can be seen in Figure 5, violet seems to be the least important colour for the respondents. It achieves the value of -6.20 while the highest value is achieved by beige with 8.23. Other colours are distributed between:
- dark grey with a value of -2.69;

- blue with a value of -0.99;

- green with a value of 1.65 .

Next we wanted to know what the replies would be to a direct question: 'What colour would you choose?'

Figure 6. Results of a direct question about the choice of colour

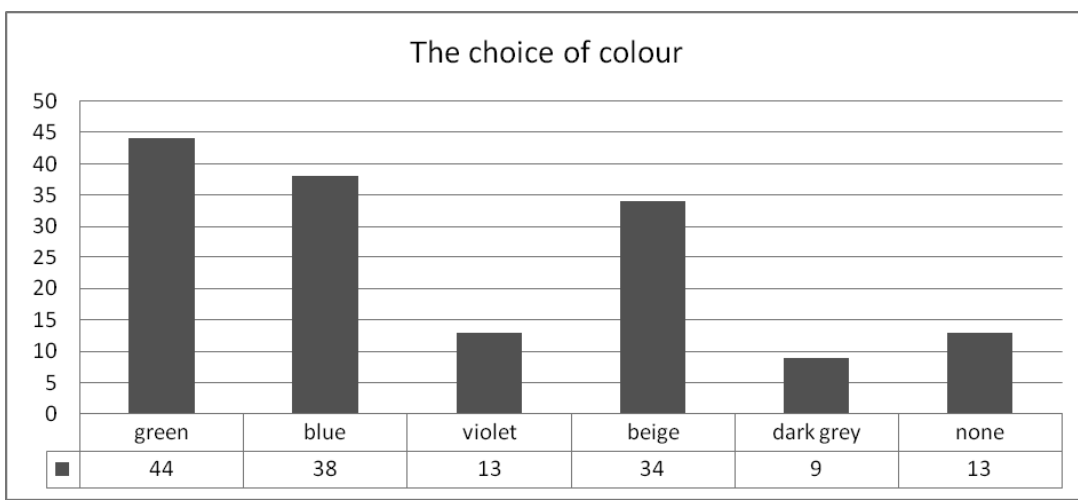


Figure 6 shows that 44 respondents $(29.1$ $\%)$ picked green. Blue was chosen by 39 respondents $(25.2 \%)$. The fewest respondents picked dark grey, namely $9(6 \%)$.

\section{Bonuses}

The following bonuses were used in the conjoint analysis study: complimentary house wine at dinner, free Wi-Fi service, free viewing of pornographic channels or free parking.

Figure 7. Level of benefit: free bonuses

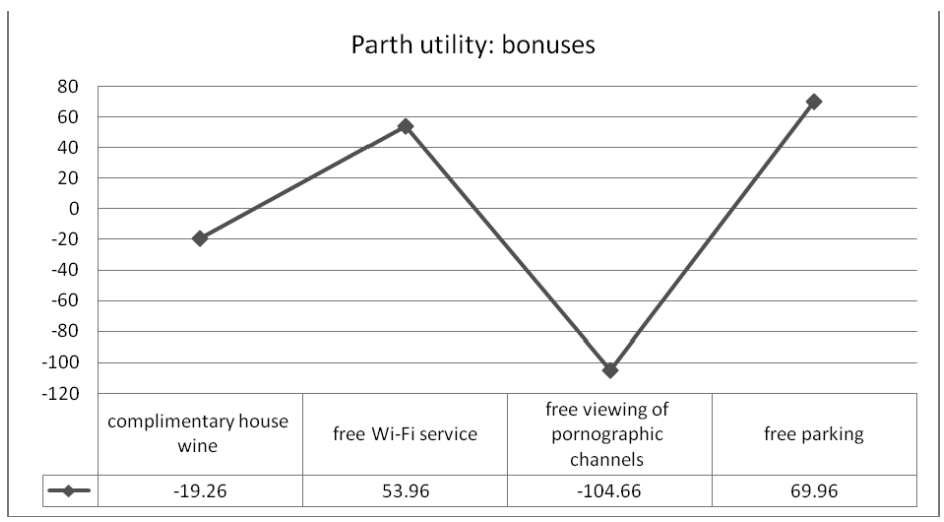

Figure 7 clearly shows that the highest value was achieved by free parking with 69.96. Free Wi-Fi Internet access achieved a value of 53.96. The two negative values were achieved by free wine at dinner with -19.26 and free viewing of pornographic channels with -104.66.

Hypothesis 3: Of the four bonuses on offer, the free Wi-Fi Internet access is the most important factor in deciding whether or not to purchase a hotel service.

The hypothesis claiming that the free $\mathrm{Wi}$ Fi Internet access is the most important factor in deciding whether or not to purchase a hotel service was disproved.

When asked which of the free bonuses respondents would select at the hotel reception upon arrival, they supplied the following answers.

Figure 8. Results of a direct question about the choice of free bonuses

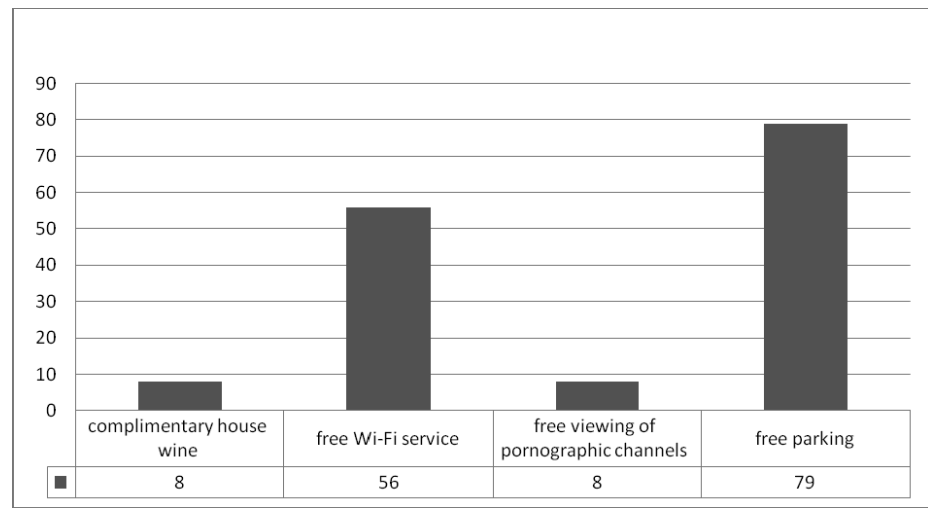


As can be seen in Figure 8, most of the respondents, namely $79(52,3 \%)$ picked free parking followed by free internet access with 56 respondents $(37.10 \%)$. Free house wine at dinner and free pornographic channels were chosen by 8 respondents (5.3\%) each.

\section{Price}

The following prices were used in the study: 64 EUR, 70 EUR, 76 EUR and 82 EUR.

Figure 9. Level of benefit: price

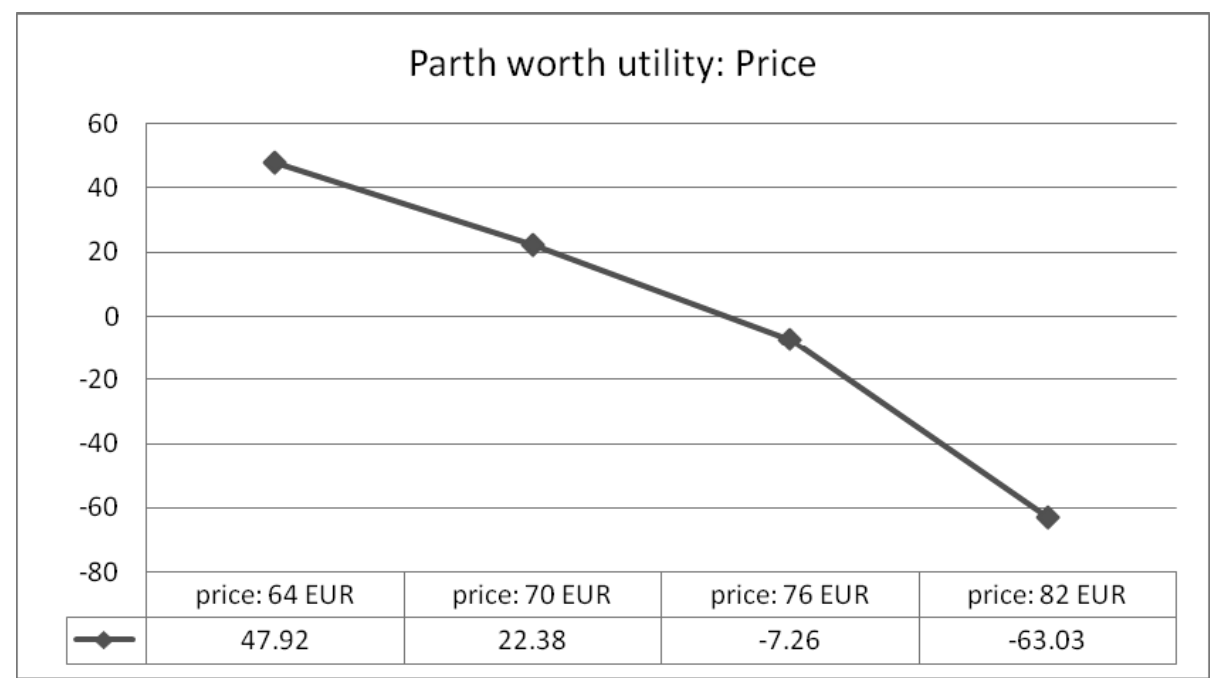

As illustrated by Figure 9, the highest value $(47,92)$ was achieved by the price of 64 EUR while the lowest value (-63.03) was achieved by the price of 82 EUR. 76 EUR was given a value of -7.26 and 70 EUR a value of 47.92 .

As opposed to colours and bonuses, we did not ask the respondents directly which price they found most appealing. It can be expected that the lowest price is the most attractive attribute per se without the other hotel service attributes.

\section{Conclusion}

According to marketing theories, price is the most important factor in the marketing. We are not trying to deny that. Rather, this paper is an attempt to point out that there is plenty of room for manoeuvre within the 64 EUR to 82 EUR price range whereby the combination of the right bonus and a raised price can still attract a consumer.

We avoided unrealistic questions such as asking about preferences for prices that are not used in practice. The analysis showed that within an acceptable price range a consumer prefers a bonus. The free parking space turned out to be the most desirable bonus, followed by free Wi-Fi Internet access. Colours did not play an important role. Although practically all hotels in Ljubljana have their rooms painted in one of the colours mentioned in the survey, we can unreservedly recommend the hotel management to carefully consider whether painting a room in a different colour is nec- 
essary; the biggest factor in the matter being the price.

The difference in price (JUB, 2011) between white paint and other paint colours is somewhere in the range of $40 \%$ to $250 \%$. The cost of labour is also higher when using paint colours other than white. The preferred choice for hotel guests when it comes to bonuses seems to be a free parking space. The cost of parking in public car parks is anywhere between 10 EUR and 20 EUR per day. In a hotel where the price of a room is between 64 EUR and 82 EUR, parking represents a large expense for a guest.

Another important amenity for hotel guests is free Wi-Fi Internet access. Businessmen usually arrive at the hotel with their own laptops or iPads and do not want to be dependent on hotel internet corners. The low level of preference for free house wine at dinner shows that hotel guests are not interested in free wine at dinner when staying in a hotel for such a short period of time. Logically, with such a high preference for the free Wi-Fi internet access there is no demand for free pornographic channels. Adult content is easily accessible on the Internet. The cost of Pay TV service is therefore too high to be justifiable. In addition, unlocked adult channels can quickly lead to guest complaints. What is needed in practice is to find a compromise between the price and bonus.

\section{References}

Addis, Michaela in Morris B. Holbrook. 2001. On the conceptual link between mass customisation and experiential consumption: An explosion of subjectivity. Journal of Consumer Behaviour 1 (1): 50-66.

Bargh, John A. 2002. Losing consciousness: Automatic influences on consumer judgment, behavior and motivation. Journal of Consumer Research 29 (2): 280-285.

Belanger, France, Janine S. Hiller in Wanda J. Smith. 2002. Trustworthiness in electronic commerce: the role of privacy, security, and site attributes. Journal of Strategic Information Systems 11 (2): 245-270.

Carbone, Lewis P. in Stephan H. Haeckel. 1994. Engineering customer experiences. Marketing management 13 (3): 8-12.

Dubrovski, Drago. 2006. Management mednarodnega poslovanja. Koper: Fakulteta za management.

Erasmus, Alet C., Elizabeth Boshoff in Deon Rousseau. 2001. Consumer decision-making models within the discipline of consumer science: a critical approach. Journal of Family Ecology and Consumer Science 29 (1): 82-90.

Kasavana, Michael in Richard Brooks. 2005. Managing front office operations.Lanssing: Educational Institute of the American Hotel \& Lodging Association.

Kotler, Philip. 1996. Marketing management - trženjsko upravljanje: analiza, načrtovanje, izvajanje in nadzor. Ljubljana: Slovenska knjiga.

Melavc, Dane. 2003. Gospodarjenje. Koper: Fakulteta za management.

Mihalič, Tanja. 1999a. Poslovanje in ekonomikaturističnih podjetij. Ljubljana: Ekonomska fakulteta.

Nightingale, Jim. 2008. Think smart-act smart. Hoboken: John Wiley \& Sons.

Niva, Mari in PaiviTimonen. 2001. The role of consumers in product-oriented environmental policy: can the consumer be the driving force for environmental improvements?.International Journal of Consumer Studies 25(4): 331-338.

Orme, Bryan. 1998. Sample size issues for conjoint analysis studies. Http://business.nmsu. edu/ mhyman/M310_Articles/CA_and_ Sample_Size.pdf (16.8.2011).

Pagon, Milan. 2011. Odločanje. Http://www.fov. uni-mb.si/studij/studijska\%20gradiva/pag on/Odlo\%C4\%8Danje.pdf (29.7.2011).

Peter, Paul J. in Jerry C. Olson. 2002. Consumer behavior and marketing strategy. New York: Irwin McGraw-Hill.

Planina, Janez. 1997. Ekonomika turizma. Ljubljana: Ekonomska fakulteta. 
Prodnik, Jadranka in Ksenija David. 2009. Poslovanje $v$ turizmu. Http://www.impletum.Zav od-irc.si/docs/Skriti_dokumenti/Poslovanje_ v_turizmu-Prodnik_David.pdf (21.8. 2011).

Rapalle, Clotaire. 2006. The culture code. New York: Brodway Books.

Reason, James. 1990. Human error. Cambridge: Cambridge University Press.

Salerno, Niel. 2008. Hotel revenue management in astagnanteconomy. Http://ehotelier.com/ hospitality-news/item.php?id=A14107_0_ 11_0_M (20.6.2011).
Walley, Keith, Stephen Parsons in Maggie Bland. 1999. Quality assurance and the consumer: A conjoint study. British Food Journal 101 (2): 148 - 162.

Toroš, Ivan. 2014. Vpliv cenovnih pasovna management cen, (Znanstvene monografije Fakultete za management Koper). Koper: Fakultetaza management.

Wikström, Solveig R. 1996. The customer as co-producer.European Journal of Marketing 30 (4): 6 - 19. 